\title{
Comentário III
}

\section{Lilia K. Moritz Schwarcz}

Departamento de Antropologia, Faculdade de Filosofia, Letras e Ciências Humanas/Universidade de São Paulo

Introdução ou como compartilhar de um belo passeio

É difícil a tarefa daquele que deve comentar, com algum rigor, um agradável passeio. Melhor é falar do ambiente, destacar as paisagens, assinalar desvios no caminho certeiro.

Esse é um pouco o perfil dessa apreciação ao texto de Mary Lucy Murray Del Priore, sobre a "história do corpo". Com a elegância de quem veste os nus, mas os deixa, ao final, mais descobertos do que no início, Mary nos convida a entender como as narrativas e os recortes históricos respondem, também, ao contexto no qual se inserem.

"Filha de seu tempo", na feliz expressão de Lucien Febvre, a história sempre refletiu sobre seu momento, iluminou novas facetas ao mesmo tempo que passava a iluminálas. Desse movimento, é claro, a percepção do corpo e sua historiografia não se encontram afastadas e é isso que nos mostra a autora.

Com ela voltamos a uma certa "pré-história" dessa história, quando em meio a uma narrativa marcadamente política começava-se a descobrir tempos quase imóveis, assinalados por ritos e cerimônias mais próximos da intimidade e do familiar. Mas foi só nos anos setenta, e ao longo da década de oitenta, que se avolumaram os trabalhos e pesquisas. É então, que rastreando tempos diversos, renomados historiadores, sobretudo franceses, voltaram-se para as éticas sexuais, o uso dos corpos, a lógica dos pecados, enfim para um mundo em que novos elementos destacavam-se dialogando com antigos domínios que até então, no 
1. Autores como Taussig (1987), R. Price (1983), Clifford \& Marcus (1991), Crapanzano e mesmo Geertz (1983) têm falado de uma espécie de crise de identidade que tem se abatido sobre uma antropologia, sobretudo americana, que na impossibilidade de falar do "outro" tem se voltado cada vez mais sobre $s i$, indagando acerca de suas próprias limitações. "Os antropólogos são uma aldeia" (1983) diz C. Geertz, numa clara alusão ao movimento contemporânco de uma certa antropologia pósmoderna. máximo, os entendiam como adorno e adereço para conclusões de maior envergadura.

Nesse movimento não só as fontes se modificaram, como as perguntas tornaram-se diversas. Pioneiro nesse sentido é o livro de Norbert Elias (cuja primeira edição data de 1939), que faz uma espécie de arqueologia dos costumes ocidentais vinculando-os ao tão estimado conceito de civilização.

Mas é mesmo nos anos oitenta que, segundo a autora, juntamente com um debate mais sistemático com a Antropologia, esse tipo de produção ganha maior evidência. Nesse caso, porém, era o corpo que estava em questão: a moda, ideais de beleza, imaginário e violência, o corpo do supliciado e da feiticeira, o corpo morto e o corpo dos mártires, corpos reclusos e teatralizados. Mary desfila por entre os diferentes livros e artigos, ora retocando a maquiagem de um ensaio, ora dando brilho a uma coletânia, às vezes delineando os traços de obras, aqui, pouco conhecidas.

Tudo isso é feito de modo a demonstrar a constituição de um campo "de um objeto capturável e unificado" - que na verdade dialoga com essa sociedade que, segundo Mary, enaltece a higiene, mas mal e mal lida com seus "novos e furiosos vírus".

Fim do primeiro passeio, começo de um outro. Toda trilha, por mais rica que seja, seleciona caminhos e evita curvas sinuosas. Talvez o maior desafio seja dialogar com essa "história do corpo", que na pista da consagração deve escapar dos essencialismos e da constituição de um campo que se define por seu objeto, mas evita problematizações. Se não é isso que faz Del Priore, podemos ao menos traçar uma linha na face e, junto com ela, pensar nos impasses de uma voga.

No reino dos indivíduos

Conformemos uma primeira hipótese que permita insistir nos contornos desse campo e da relação estimada entre Antropologia e História. Assim como a História foi ora mais política, ora mais social, nesse caso, talvez essa "história do corpo" seja produto e produtora desse processo crescente de individualização. Separados das sociedades dos estamentos, conformamos cada vez mais comunidades de individuos que privilegiam suas singularidades e diferenças. Nesse sentido, e apesar da evidência da globalização, tem despontado como fenômeno uma série de episódios de afirmação de particularidades, de reiteração de tribalizações e mesmo o lado mais obscuro dessa história: o racismo.

Mas se esse tema nos levaria a um outro caminho, o que importa destacar é que enquanto a História, para além das grandes estruturas, dialoga com a Antropologia a partir dos detalhes, "das pistas", na versão de Ginsburg (1989), ou com a idéia de que a cultura é microscópica, conforme assinala C. Geertz (1978), já na Antropologia a crítica ao particular é de tal radicalidade que tem tendido a inviabilizar qualquer tentativa de produção científica. Entre a crítica ao sujeito e a rebelião do objeto - que não mais se enxerga nos modelos do antropólogo - a disciplina, na interpretação pós-moderna, vive uma espécie de "crise do relativismo e da exaltação essencial das diferenças"l. 
nas coincidências reveladas, preocupação. Herdeiros de um processo que fez do sujeito de classe, senhor absoluto de seu destino e de seu corpo, vemos duas disciplinas, por caminhos diversos, selecionarem um objeto semelhante e o transformarem em "evento". A questão não está, porém, no local recortado, mas na afirmação da particularidade, mesmo em meio ao reconhecimento da longa duração. Assim, se na Antropologia chegamos ao impasse de ver antropólogos abrirem mão de seus "nativos" para analisarem a si próprios (Geertz 1983), ou dividirem formalmente sua narrativa, para darem lugar à fala de seus informantes (Price 1983), talvez seja hora de pensar em uma reflexão comparativa que nuance a afirmação da identidade.

Quem sabe além de reagir tão somente a uma sociedade da "medicamentalização", mas que lida "com males cuja cura se está longe de alcançar", estamos diante dos impasses de um novo final de século, que frente à afirmação do indivíduo, no final do XIX, agora pensa a sua radical essencialidade. - corpo sempre foi um local privilegiado para a inscrição de leis, códigos e violências, como bem mostrou P. Clastres (1982); um espaço para a aplicação de técnicas corporais (Mauss 1974); matéria para o suplicio exemplar. Mas se até então o corpo remetia ao grupo, como pensá-lo, agora, como marca do sujeito que carrega nome e condição?

Na Antropologia esse tema tem levado a impasses e a uma discussão, no limite, sobre a ética (Taussig 1987) e acerca da possibilidade de, de fato, conhecer espaços da intimidade do assim chamado "outro". E na História? Por que mais exatamente, uma voga francesa se apodera do tema e o faz virar um grande fenômeno? Pode ser que, longe de "um objeto capturável e unificado", estejamos diante de várias historicidades, cujo objeto - o corpo - é quase um pretexto. Afinal, nos usos pragmáticos que tanto a História, como a Antropologia fazem uma da outra, muitas vezes está em questão não a disciplina, mas o que dela se recorta. A provocação é indagar se é possivel apoderar-se de um instrumental retirando-o de seu contexto intelectual.

Antropologia e História: as coincidências não estão nos objetos

Quando Alice encontrou-se em uma armadilha daquelas, mal sabendo se deveria beber do líquido de uma ou de outra garrafa, já que as duas apresentavam o mesmo rótulo, dirigiu-se a Humpty Dumpty e perguntou a seu estranho amigo:

- Como posso escolher um dos dois vasilhames se os nomes são iguais?

fez esperar:

A resposta que, no caso, era muito melhor do que a pergunta, não se

- Aquela que segue nomes, no mais das vezes se engana.

Fazendo um uso maroto da passagem de Carrol, em Alice no país das maravilhas, talvez possamos pensar que mais do que procurar coincidências nos objetos, quem sabe são questões comuns que aproximam as duas disciplinas. $\bigcirc$ que significa ir ao encontro do "outro" senão procurar não o que há em comum, mas outras historicidades (Lefort 1979), ou mesmo cosmologias que por vezes se encontram, mas cujo destino lhes é particular (Sahlins 1990); aí está uma tarefa que nos aproxima. Não se vai ao passado apenas com a intenção ingênua de,
2. Referência ao conceito utilizado por $\mathrm{M}$. Sahlins (1990), que distingue a noção de "fato", da noção de "evento": um acontecimento com ampla significação cultural. 
tal qual um projeto realista, reconstituíto, mas talvez porque essa tarefa aumenta a compreensão sobre nós mesmos. Como diz Mary "o bom de inquirir o passado, é que esse nos permite reconhecer a linguagem de nosso próprio corpo, recuperando gestos que se repetem a séculos".

Fiquemos com a primeira parte da afirmação acima: o que procuramos no "outro" é sempre a nós mesmo. Problematizemos a segunda: o que encontramos não é repetição; mas sim releitura, re-significação.

Convido agora a um novo passeio. Rousseau, que, segundo Lévi-Strauss (1976), foi o pai da etnografia, em seu Discurso sobre a origem e os fundamentos da desigualdade entre os homens, desabafava: "Toda a terra está coberta de nações, mas só thes conhecemos os nomes e nos atrevemos a julgar o gênero humano", ou afirmava que "quando se quer estudar os homens, é preciso olhar perto de si; mas para estudar o homem, é preciso aprender a distinguir o olhar; para descobrir as propriedades é preciso primeiro observar as diferenças" (Essai sur l'origine des langues, cap. VIII.

Aí estavam reunidas duas propriedades fundamentais da etnografia. Em primeiro lugar, Rousseau preconizava o estudos dos homens mais distantes, mas se dedicava a um homem particular: ele mesmo. Em segundo, a vontade de identificação com o outro caminhava sempre, lado a lado, com a recusa de si próprio (Lévi-Strauss 1976). Com efeito, em sua prática, o etnólogo constrói modelos lassim como faz Rousseau com o "bom selvagem", sobretudo um modelo para pensar a civilizaçãole descobre a si mesmo.

Aceitar-se no "outro", recusar-se em si mesmo, eis o princípio que funda as ciências humanas: "Ei-tos portanto estrangeiros, desconhecidos, nulos (...). Mas eu, destacado deles e de tudo, que sou eu? Eis o que me resta descobrir" (Primeira promenade).

Em questão está, portanto, menos a capacidade que temos de ver o "outro" e atuar nesse sentido e mais a noção de que a identidade é sempre um jogo polar: o conhecimento da alteridade passa sempre pelo crivo do "eu" ou é preciso tomar as diferenças para chegar mesmo às propriedades.

Foi Marcel Mauss quem ensinou a privilegiar essa comunicação com o objeto e buscou verificar como um sistema eficaz de símbolos vai inserir-se no individual mais profundo, sem ter que escolher entre o particular e o coletivo. Uma certa razão alargada deveria dar conta das dicotomias e da variedade das culturas, sem que fossem impermeáveis entre si, chegando até o irracional da magia e do dom (Merleau-Ponty 1980).

Na obra Ensaio sobre a dádiva (1974), categorias nativas como Hau e Mana representavam não efeitos da sociedade, mas a própria sociedade. A possibilidade de se chegar ao "outro", não pelo que trazia de singular, mas a partir do que era comum. Como "o espírito da coisa dada", elementos da cultura Maori permitiam refletir sobre o que há de universal nas culturas, para além de suas particularidades locais.

Não se trata, dessa maneira, de optar pela versão "primitiva", nem muito menos de reduzir sua lógica a um modelo desigual, mas sim de instalar terrenos de inteligibilidade sem reduções ou transposições fáceis. A meta é alargar a nossa razão.

Porfanto, se há algo que inspira na Antropologia são menos os seus 
objetos - "a estética, a cosmética, a ergonomia, o esporte, a identidade, os hábitos corporais e toda uma infinita gama de assuntos relativos ao corpo", como afirma Mary -, mas sobretudo "uma maneira de pensar que se impõe quando o objeto é 'outro' e que exige a nossa própria transformação" (Merleau-Ponty 1980: 1991.

Talvez o corpo seja mesmo bom para pensar, mas sua análise revela menos o retrato de outro corpo já que fala sempre de um princípio que o constituiu nesse contexto: a percepção ocidental contemporânea sobre a propriedade. Uma volta à "longa duração" de Braudel, seria, por certo, iluminador. Com efeito, aí está um conceito bastante utilizado, porém pouco refletido e mesmo definido. Estaríamos ou não longe da noção de estrutura de lévi-Strauss, que privilegia a sincronia e encontra a diacronia apenas nas versões particulares? Será que a conclusão de Marc Bloch em Os reis taumaturgos (1929/1993) nos fala de uma guinada na historiografia que se afasta do fato em si e procura estruturas? Afinal, concluía o grande historiador, que mais do que procurar pela cura, era preciso reflefir sobre uma história do milagre, da vontade do milagre.

Estamos e não esłamos longe do tema do ensaio em questão. Na verdade, quando Lévi-Strauss escrevia o ensaio chamado "O feiticeiro e sua magia" (1975), relia Marc Bloch ao tratar do fenômeno do xamanismo. Segundo o etnógrafo, aquele que procurava pelas poções e antídotos corria o risco de nada encontrar. Era a crença no xamã que lhe conferia eficácia.

Qual é, portanto, o lugar dessa "História do corpo" e seu diálogo com a Antropologia? Parafraseando Ginsburg, em seu livro História noturna, é possivel dizer que "entre a profundidade abstrata da estrutura (privilegiada por Lévi-Strauss) e a concretude superficial do evento (...) nessa faixa intermediária provavelmente se joga, em meio a convergências e contrastes, a verdadeira partida entre Antropologia e História" (Ginsburg 1991: 35).

É assim que ao procurar atitudes, comportamentos e mentalidades, a História ganha um novo esłatuto e encontra um olhar, também, antropológico. Mas é preciso avaliar se se trata de uma revolução na historiografia francesa ou apenas uma ampliação nos objetos de estudo. No que insisto, portanto, é em que deve haver um compromisso com esse jogo em que os objetos são piões, mas é a própria estrutura $e$ as questões que formam o conteúdo da partida que vai ser disputada.

Para terminar: sobre uma história do corpo em um local de pouca privacidade

Termino com uma curiosidade. Se sobre o corpo criaram-se representações, discursos e marcas, de que corpo se fala? Como pensar nesse ramo da história em meio ao contexło brasileiro, tão caracterizado pela falta da intimidade? Como adequar o país da escravidão e dos trópicos, do Estado ao longe, a essa reflexão sobre o corpo?

São os próprios livros de Del Priore que nos mostram, entre outros, que mais vale pensar na "excelência da cópia" do que na importação desavisada. Não se constrói uma historiografia francesa tropical, mesmo porque quando se procura pelo modelo ele já se alterou em e no contexto. Mas mesmo assim vale sempre a pena problematizar a idéia de que os rótulos no mais das vezes escondem 
conteúdos diversos. É assim no terreno da cultura: se a emissão é singular, a recepção é sempre plural, pois "a cultura é pública, e seu significado está sempre em risco" (Sahlins 1990).

nosso desafio é pensar em corpos que não são nossos, que são propriedade de outros e que evidenciam crateras diante de modelos que partem da afirmação iluminista, que instituiu o humanismo: o direito à igualdade e à propriedade. O corpo escravo é por princípio o não corpo. Servus non habet personam: o cativo era por excelência um sujeito sem corpo, nome, antepassados ou bens próprios.

Por outro lado, em uma terra em que o Estado e suas instituições estão tão ausentes, como pensar na intimidade? Não é dizer que não há qualquer espaço público no Brasil, mas que seu lugar será o da re-criação. Essa não é tarefa, nem o objeto do ensaio de Del Priore, mas um bom passeio leva sempre ao desejo de outras viagens.

Termino com a autora da citação que dá início ao texto: Mary Douglas. Parece-me que é ora de abrir mão dos famosos "padrões culturais", que consagraram a escola americana de Antropologia, que de tão essencializados acabaram por pensar a cultura de forma não contextual e quase autônoma. A "história do corpo" pode ser um bom mote para entendermos como a cultura se faz de modo circular e que, no limite, estamos sempre reagindo a dois extremos. De um lado, o significado se dá em contexto e circunstância. De outro, porém, cada cultura é sempre um espelho deformado que altera o estímulo que vem de fora, em função de um quadro cultural que the é anterior. Nesse sentido, uma História do corpo a la brasileira será sempre um jogo sensível entre estruturas do passado e projetos do presente.

Quanto ao presente... é sobre ele que nos debruçamos para constituir novos campos, se não de investigação, ao menos de curiosidade. Estamos falando de uma História que se detém nos corpos não pelo tipo de objeto que prescrevem, não em função de um projeto que pretenderia dar conta de todo o campo humano (com acontecimentos datados em um tempo serial). Trata-se de uma História que, ao reconhecer a especificidade de seu recorte, encontra um tempo diverso, em que as diferentes cosmologias recortam séries de acontecimentos que estão além e aquém do dia-a-dia. Falam de um outro tempo dado pela sincronia, em que o grande encontro é do "eu": sujeito de inquietações e reflexões. Como diz Merleau-Ponty, "não o pensador que quer explicar ou construir o mundo, mas aquele que busca aprofundar nossa inserção no ser" (1980: 196).

Na verdade, foi o inventário tão bem feito por Mary que me levou a pensar, sobretudo, nesses jogos entre Antropologia e História. Priorizar as questões para além dos objetos seria uma boa forma de abandonar um critério só positivo frente a delimitação das ciências. Mas mais do que isso, o Dossiê revela como não existem campos finitos quando se trata de pensar nas temáticas históricas. Cada nova divisão implica um elenco de possibilidades; abre espaços até então vedados ao olhar.

Exercício profícuo, essa nova "história do corpo" só faz demonstrar a riqueza e a pluralidade das culturas. Termino com Merleau-Ponty, que dando sempre a benção às novidades do saber, aconselha: "é preciso traçar o maior catálogo possível de categorias; é preciso partir de todas aquelas que pudermos 
saber que foram usadas pelos homens. Ver-se-á, então, que ainda há muitas luas mortas, pálidas ou obscuras no firmamento da razão" "Merleau-Ponty 1980: 195). 